\title{
Enfoque de redes sociales en las migraciones de América latina hacia Francia
}

\author{
Lina Bassarsky \\ CERPOS, Centre de Recherche Population et Sociétés, \\ Université Paris X - Nanterre
}

\begin{abstract}
Se analizan comparativamente cuatro flujos migratorios de latinoamericanos hacia Francia: el exilio sudamericano, la "fuga de cerebros", la migración laboral de un grupo nacional y la "diáspora" haitiana. El foco de atención es desplazado desde categorías clasificatorias tradicionales hacia un nivel "meso" o de intermediación entre factores micro y macrosociales. Se observan diversos tipos y funciones de redes de latinoamericanos que ilustran cuatro usos diferentes del concepto de red. Se concluye que la perspectiva de redes puede aportar conocimientos oportunos, a pesar de su aplicación frecuentemente difusa y la falta de consenso en el seno de las ciencias sociales.

Palabras ClaVe: migraciones, América Latina, Francia, redes sociales, teoría social, exilio, fuga de cerebros, migración de trabajo, diáspora.

We comparatively analyse four types of migratory flows from Latin America to France: the South American exile, the "brain-drain", the labour migration of a national group and the Haitian Diaspora. The focus of analysis shift from traditional macro social migratory categories to the "meso-level" or the intermediation level, between macro and micro social factors. We point up different types and fonctions of Latin Amercian social networks that illustrate four different uses of the concept of network. Despite its frequently diffuse application and its lack of consensus in social sciences, we conclude that the network approach can provide appropriate knowledge on a wide range of migratory modalities.
\end{abstract}

KEYwORDS: migration, Latin America, France, social networks, social theory, exile, brain drain, labour migration, diaspora.

\section{Introducción}

A pesar de sus antecedentes históricos y sus particularidades recientes, en la mayoría de los países europeos los conocimientos sobre la dinámica de la migración latinoamericana, así como de las condiciones de vida de los inmigrantes, son aún limitados. En el caso de Francia, los estudios socio-demográficos y sociológicos relativos a los flujos latinoamericanos o a las condiciones de vida de los inmigrantes instalados son escasos, si bien 
existe un cúmulo significativo de literatura acerca de la historia de los lazos culturales y políticos que unen las sociedades latinoamericanas y francesa. Evidentemente esto se explica, al menos en parte, porque éste constituye un fenómeno de modesto tamaño, en comparación tanto con los destinos más importantes de la emigración latinoamericana, como con los principales orígenes de la inmigración en Francia. Sin embargo, algunos de estos grupos han despertado la atención de investigadores interesados en la región de América Latina o en perfiles migratorios específicos. Por otro lado, la inmigración de latinoamericanos encuentra ya cierto eco en la agenda de discusiones entre la Unión Europea y los representantes de la región.

En nuestra opinión, a pesar de constituir un fenómeno relativamente pequeño en términos demográficos, la migración de América Latina a Francia constituye un objeto interesante de estudio de selectividad migratoria, en el que se conjugan una heterogeneidad en los perfiles sociales de inmigrantes, provenientes de diferentes orígenes y oleadas migratorias, y en consecuencia, la coexistencia de distintas generaciones - lo que permite eventuales análisis del cambio intergeneracional y de las llamadas "segundas generaciones"-. Es preciso aclarar que esta heterogeneidad migratoria ligada al propio carácter diverso de la región, no objeta, sin embargo, la presencia de una unidad socio-histórica y cultural que permite que "lo latinoamericano" remita, en el plano de las migraciones, a una mera unidad geográfica de procedencia.

Tal como la mayoría de los estudios que tratan sobre determinados flujos migratorios, los desplazamientos de latinoamericanos hacia las regiones desarrolladas han sido descritos desde la perspectiva de categorías clasificatorias macrosociales. Por un lado, encontramos las referidas a la evolución temporal de los movimientos, que distinguen entre los "inmigrantes definitivos", "temporarios", "transeúntes", etc. (por ejemplo, la propuesta por G. Standing). Por otro lado, se hallan las basadas en los motivos de la migración, que establecen diferencias entre la "migración laboral", las migraciones forzadas, de exilio, de estudios, de personas altamente calificadas, etc. Otro ejemplo de clasificación es la que propusieron M. Picouet y H. Domenach en los años ochenta que, combinando los dos criterios anteriores (temporalidad y motivos), distinguieron entre "movimientos reversibles renovados", "esporádicos", "movimientos irreversibles forzosos", "provocados", "voluntarios", etc.

Todo sistema clasificatorio implica una relativa simplificación de una realidad siempre más compleja. En este caso, el acento sobre la visión 
macrosocial aclara poco sobre el nivel de los comportamientos, y sobre situaciones que se modifican a lo largo del tiempo, corriéndose así el riesgo de dotar el análisis de simplificaciones y a prioris.

Por ejemplo, muchos exiliados políticos de los años setenta que ejercían profesiones "liberales" en sus sociedades de origen debieron, al momento de su llegada a Francia, buscar empleos precarios y desarrollar estrategias de vida que no diferían de aquellas desplegadas por los inmigrantes "laborales". Sería más pertinente, por ejemplo, pensar en un sistema dinámico que incorpore una visión sobre el cambio, más que en categorías agregadas o rasgos atribuidos ("exiliado", "trabajador", "altamente calificado", etc.), ya que dichos rasgos no varían a lo largo del tiempo.

Si bien estas observaciones son válidas, debemos aceptar asimismo que si una larga tradición de estudios retoma dichas categorías migratorias, es porque las mismas aluden a fenómenos de carácter más o menos típico. Es cierto, además, que estas categorías dan cuenta de ciertas representaciones construidas y plasmadas en instituciones sociales, como las empleadas en el sistema de clasificación burocrática (permisos de residencia, de trabajo, asistencia social, refugio, etc.).

En definitiva, se trata de visiones diferentes del objeto de observación. De este modo, dar prioridad a otros criterios de análisis puede aportar una serie de análisis focalizados sobre otros aspectos de la experiencia migratoria distintos de los motivos o la temporalidad de la migración. Por estas razones, hemos retomado algunos de los ejemplos estudiados sobre migraciones de América Latina hacia Francia, para analizarlos desde un ángulo distinto. Nos referiremos a las migraciones de exilio, la "fuga de cerebros", la migración laboral, y a la "diáspora", no priorizando la descripción del grupo migratorio, sino focalizando los mecanismos de redes sociales que pueden haber actuado tanto posibilitando el desplazamiento, como en etapas posteriores de la experiencia migratoria.

Hemos querido explorar el enfoque de redes sociales teniendo en cuenta la gran difusión que alcanzó el mismo en los últimos tiempos en el campo de los estudios migratorios. Dicha expansión sugiere algunos comentarios:

En su sentido más abstracto, una red puede ser definida como un conjunto de relaciones que actúan alrededor de algún principio organizador subyacente. Las ciencias sociales han adoptado el concepto de "red social" a lo largo de un recorrido de ideas sin dudas íntimamente ligado la historia del estructuralismo, que ve en ellas estructuras duraderas de relaciones 
sociales. ${ }^{1}$ Quizás sea oportuno mencionar la distinción entre la tradición sociocéntrica (que explica las propiedades de un conjunto de conexiones entre un grupo de "nodos") ${ }^{2}$ y la tradición egocéntrica (que parte de las conexiones que pueden trazarse a partir de un ego dado - unidades o individuos-). ${ }^{3}$

Más específicamente, en los últimos tiempos los estudios migratorios retomaron la idea de red (con aplicaciones derivadas de ambas tradiciones) como parte de un conjunto de esfuerzos tendentes a renovar las teorías existentes sobre las migraciones. A grandes rasgos, dichas teorías habían propuesto explicaciones ya sea de nivel macro-estructural (como las teorías clásica y neoclásica de los factores de atracción y repulsión, la teoría del mercado de trabajo segmentado, la de los sistemas migratorios o la de la transición de la movilidad); o bien de nivel de los factores micro-individuales (en su vertiente neoclásica, o la llamada "nueva economía de las migraciones"). ${ }^{4} \mathrm{El}$ enfoque de redes intenta, por su parte, situarse en lo que se piensa como el nivel "meso-social" o de intermediación entre ambos niveles. Esto implica la relación dinámica entre individuo y estructura, reconociendo efectos estructurantes de las redes sobre los individuos, así como grados de libertad del individuo para la interacción. De esta manera, el viejo y conocido concepto de "cadena migratoria"s se vio ampliado por el

1 Para una síntesis de dicho recorrido: Mercklé, Pierre: Les origines de l'analyse des réseaux sociaux, Centre national d'enseignement à distance (CNED) Ecole normale supérieur, Lettres et sciences humaines, 2003-2004 (disponible en Internet). En español, puede consultarse: Requena Santos, Félix: Análisis de redes sociales. Orígenes, teorías y aplicaciones, CIS (Centro de investigaciones sociológicas) / Siglo XXI, Col. Monografías, n. ${ }^{\text {1 }}$ 198, Madrid, 2003, capítulo 1.

2 El término nodo, aplicado en ciencias sociales al análisis de redes, invoca rápidamente la forma en que las ciencias sociales (o las corrientes ligadas al positivismo) adoptan, en paralelo, términos provenientes de las ciencias duras.

3 Ver por ejemplo Molina, José Luis: El estudio de las redes personales: contribuciones, métodos y perspectivas, Empiria, julio-diciembre 10, 2005, págs. 71-106.

4 Respecto al nivel "meso", puede consultarse: Faist, Thomas: "The crucial meso-level" en Hammar, T.; Brochmann, G.; Kamas, K., y Faist, T. (directores): International migration, immobility and development, Oxford, Berg, 1997, págs. 187-217. Una síntesis de las diferentes teorías sobre migraciones puede consultarse en: Slotnik, Hania: "Théories sur les migrations internationales" en Caselli, Graziella; Vallin, Jacques, et Wunch, Guillaume (dirs.): Démographie: analyse et synthèse. IV Les déterminants de la migration, INED, París, 2003, cap. 59. También, los textos clásicos de Massey, Douglas, et al.: "Theories of International Migration: a review and appraisal", Population and Development Review, vol. 19, n. ${ }^{\circ}$ 3, 1993; Massey, D.; Arango, J.; Hugo, G.; Kouaouci, A.; Pellegrino, A., y Taylor, E.: Worlds in Motion: International Migration at the End of the Millennium, Oxford University Press, Oxford, 1998. Estos fueron retomados en: Arango, Jorge: "Expliquer les migrations: un regard critique", Revue internationale de sciences sociales, n. ${ }^{\circ} 165,2000$, págs. 283-296.

5 Las cadenas migratorias se refieren al mecanismo a través del cual ciertos flujos se perpetúan, gracias a las condiciones creadas por un grupo de inmigrantes pioneros. El principio del mecanismo señala que las relaciones sociales en el espacio perpetúan las migraciones en el tiempo. 
de "red de inmigrantes", "redes migratorias", o "redes sociales" a secas, haciendo referencia a las relaciones interpersonales e institucionales entre antiguos inmigrantes, inmigrantes potenciales y no inmigrantes de las regiones de origen y destino, según una muy citada definición perteneciente a la obra conjunta de D. Massey y otros autores. ${ }^{6}$

En definitiva, hasta el momento las ciencias sociales no han mostrado total consenso con respecto al concepto, de modo que los usos son vastos y las definiciones, teorías y métodos adoptados pertenecen a las más diversas extracciones disciplinarias o epistemológicas.

En el campo de las migraciones, no son infrecuentes los trabajos que carecen de posicionamiento teórico o metodológico explícito, alimentando el pesimismo de los pronósticos más escépticos acerca de la utilidad del enfoque, o la crítica de sus más entusiastas defensores. Sin embargo, tal es la capacidad explicativa que se suele atribuir a los mecanismos de redes, que puede sugerirse que la idea de "red" (social o migratoria) ha reemplazado a la de "estado", como concepto estructurador del pensamiento sobre las migraciones internacionales.

Lo que en todo caso nos importa resaltar aquí es lo que podría considerarse la base del enfoque, que constituye el fundamento de la sociología de G. Simmel: son las interacciones y las relaciones entre los individuos y no los individuos mismos y sus atributos lo que constituye los objetos elementales de la sociología. Dicho autor influyó en la sociología estructural que sistematizaría el análisis de redes sociales. El objeto fundamental de la sociología debe ser considerado entonces a un nivel "intermediario", es decir, las "formas sociales" que resultan de la interacción entre los individuos. $^{?}$

\section{Algunos trazos de la migración de latinoamericanos hacia Francia}

Antes de comenzar con la tarea principal de nuestro análisis, delineemos brevemente los trazos de esta migración.

Los primeros flujos significativos de latinoamericanos que se dirigieron hacia Europa dan cuenta de forma preponderante de la llamada "fuga de cerebros" latinoamericana y los movimientos de exilio provocados por

6 Massey, Douglas, et al: "Theories of Internacional...".

7 Traducción propia en base a Mercklé, Pierre: Les origens de l'analyse... 
las dictaduras de América del Sur. Dichos flujos, observados durante las décadas de 1950 a 1980, dieron lugar tanto al asentamiento de comunidades de latinoamericanos, como a importantes movimientos de retorno a los países de origen. Desde mediados de los años 1990 y hasta la actualidad, el fenómeno emigratorio desde América Latina se encuentra en expansión y adquiere relevancia cuantitativa, volcándose especialmente hacia los países donde existían ya fuertes lazos históricos, especialmente hacia España. En particular, a partir de la década de 2000 el agravamiento de las crisis de carácter socioeconómico o político-institucional en varios países de la región ha constituido un importante factor de expulsión hacia las regiones prósperas. Por otro lado, el endurecimiento de la política internacional e inmigratoria de Estados Unidos desde hace un quinquenio, tuvo como consecuencia una mayor diversificación de los destinos y del aumento de la circulación migratoria.

En el caso europeo, la fuerte regionalización de los mercados de trabajo, ligada a la relativa homogeneización de políticas migratorias y laborales y las disposiciones de la libre circulación intra-europea a partir de la abolición de las fronteras en el "espacio Schengen", sumadas al reconocimiento de la nacionalidad europea a descendientes de antiguos emigrantes transatlánticos (lo que se conoce como el "retorno diferido entre generaciones") constituyen factores que facilitan los desplazamientos y abren las puertas a la circulación entre distintos países.

El crecimiento de estas nuevas corrientes evocó la metáfora de la "inversión" de la dirección de los flujos de europeos hacia el "Nuevo mundo", de los siglos XIX y XX, abriendo así un campo de estudio emergente. A propósito, es oportuno notar que la "presión" migratoria latinoamericana ya ha llevado a la Unión Europea a la introducción progresiva de la exigencia de visado para los ciudadanos de Colombia, Perú, Ecuador, y Bolivia.

Francia constituye uno de los nuevos destinos, aunque continúan predominando los países del sur europeo como las regiones de llegada predominantes del continente. Esta nueva migración es actualmente objeto de investigación, cuyos primeros resultados la describen bajo diversas formas de migración laboral o estudiantil. Siendo una migración reciente, resta la tarea de continuar los estudios para ir dando cuenta de la evolución de tales movimientos.

El censo de población prevé una estimación de la dimensión y composición de la población inmigrante y extranjera en un determinado 
momento. ${ }^{8}$ Puesto que el objeto de nuestro trabajo lo constituyen las experiencias de migración de latinoamericanos, aquí hacemos referencia sólo a la población inmigrante, independientemente de su nacionalidad. Es decir, el censo de población define como inmigrante latinoamericano a la persona nacida en algún país de América Latina con una nacionalidad de nacimiento distinta a la francesa, no incluyendo a los latinoamericanos nacidos en Francia (los que formarían parte de la "comunidad de latinoamericanos"). Como lo indica el gráfico 1, las poblaciones de inmigrantes (nacidos extranjeros fuera de Francia) y extranjeros (con una nacionalidad distinta a la francesa) son poblaciones divergentes, pero se superponen parcialmente.

\section{GRÁFICO 1}

\section{EXTRANJEROS E INMIGRANTES}

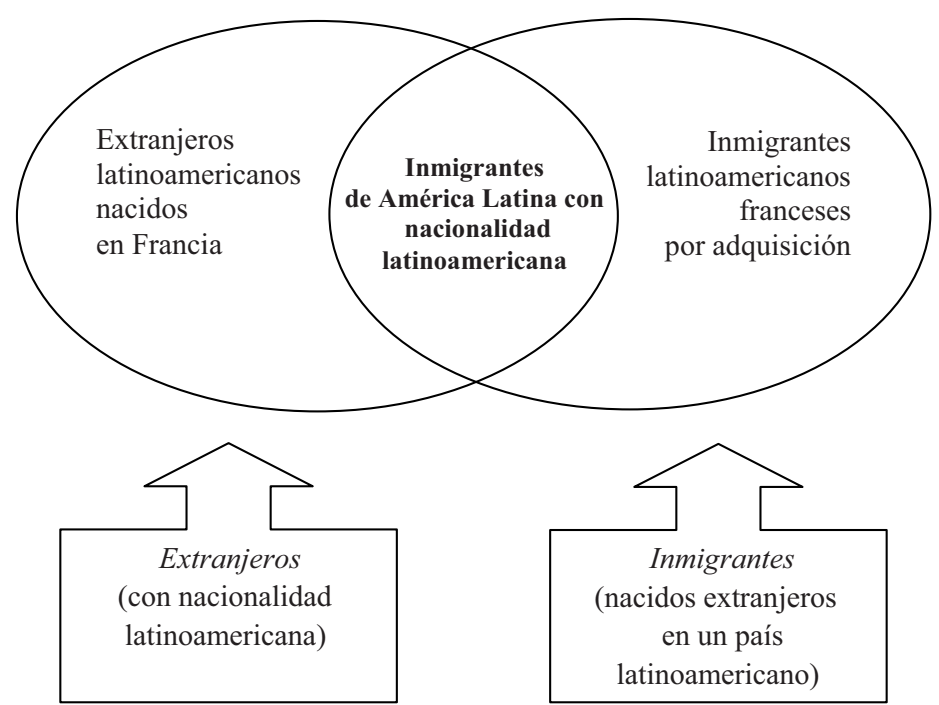

8 La metodología del relevo censal francés ha sido modificada a partir de 2004, volviendo más inexactas las estimaciones cuantitativas para pequeñas subpopulaciones, por lo que preferimos presentar los datos de 1999. La comparación con los dos censos anteriores muestra una evolución en el número de inmigrantes procedentes de América Latina y El Caribe de casi 6\% de 1982 a 1990; y de 4\% de 1990 a 1999; según cálculos propios en base a: INSEE, Recensement de la population, Mars 1999, Tableaux thématiques, Explotation complémentaire, Population immigrée. Population étrangère, CD Rom, marzo 2002. Respecto a la idea común de que existía una gran subestimación de la población inmigrante, debido a la situación de ilegalidad de una parte de ella, existen estudios especializados que evalúan que dicha subestimación no varía significativamente con respecto al subregistro general, estimado débil, de la fuente censal. 
En 1999, alrededor de 4.310.000 inmigrantes residían en la Francia metropolitana, es decir el 7,4\% de la población total, proporción constante desde 1975 (ver cuadro 1). Europa y África acumulan más de 4/5 del total de la inmigración, seguidas por Asia, con casi el 13\% de los efectivos. El total de continente americano representa sólo el 3\% de los inmigrantes, mientras que los 20 países de América Latina representan el 2\% del conjunto de la población inmigrante (estimación previa a la última oleada de principios de 2000). En último lugar se sitúa Oceanía, cuyo aporte al total es casi nulo.

\section{CUADRo 1}

DISTRIBUCIÓN DE LOS INMIGRANTES POR REGIÓN Y CONTINENTE DE ORIGEN. FRANCIA METROPOLITANA, 1999

\begin{tabular}{lrr} 
País de nacimiento & \multicolumn{2}{c}{ Inmigrantes } \\
\hline Total & Efectivos & $(\%)$ \\
\hline \multicolumn{1}{c}{ América Latina (20) } & $\mathbf{4 . 3 0 8 . 5 2 7}$ & $\mathbf{1 0 0 . 0}$ \\
\hline América del Norte (2) & $\mathbf{8 3 . 9 8 7}$ & $\mathbf{1 . 9}$ \\
$\quad$ Otros países de América & 41.437 & 1.0 \\
\hline Total América & 1.920 & 0.0 \\
\hline \multicolumn{1}{c}{ Unión Europea (14) } & 127.344 & 3.0 \\
$\quad$ Otros países de Europa & 1.631 .329 & 37.9 \\
\hline Total Europa & 303.429 & 7.0 \\
\hline \multicolumn{1}{c}{ Países del Magreb (3) } & 1.934 .758 & 44.9 \\
\hline Otros países de África & 1.298 .499 & 30.1 \\
\hline Total África & 393.611 & 9.1 \\
\hline Total Asia & 1.692 .110 & 39.3 \\
\hline Total Oceanía & 550.166 & 12.8 \\
\hline \hline
\end{tabular}

Fuente: elaboración propia a partir de INSEE: 2002 (RP 1999, explotación principal, cuadros CD-N1 y CD-N3). 
La composición por países refleja la diversidad de dicha migración, teniendo en cuenta que la región de América Latina es vasta y heterogénea en múltiples aspectos de su conformación social, política y económica y, consecuentemente, de su historia migratoria. En 1999 Haití y Brasil constituían los orígenes más representados, cuya población de inmigrantes representaba más del $40 \%$ del total de latinoamericanos. Si se suma Colombia, se alcanza el 54\%. Chile, Argentina y Perú les siguen con un $27 \%$, mientras que los 14 países restantes no alcanzan más del $19 \%$ del total (ver Cuadro 2). Su pasado colonial hace de Haití un caso particular de país de emigración latinoamericana a Francia, al que volveremos más adelante al hacer referencia al ejemplo de la "diáspora".

Otro fenómeno que podemos constatar a partir de los datos del cuadro 2 es la diferente conformación por sexo de los inmigrantes latinoamericanos. El índice de masculinidad (IM) - que representa la cantidad de varones por cada 100 mujeres - muestra una predominancia femenina en todas las nacionalidades. ${ }^{9}$ La pirámide de sexo y edad (gráfico 2) confirma dicho predominio femenino, y muestra una población relativamente joven.

\section{CUADRO 2}

\section{DISTRIBUCIÓN DE LOS INMIGRANTES LATINOAMERICANOS SEGÚN PAÍS DE NACIMIENTO. FRANCIA METROPOLITANA, 1999}

\begin{tabular}{lccc} 
País de nacimiento & \multicolumn{3}{c}{ Inmigrantes } \\
\hline Haití & 19.159 & 22.8 & 80.6 \\
Brasil & 14.913 & 17.8 & 68.3 \\
Colombia & 10.983 & 13.1 & 78.9 \\
Chile & 9.638 & 11.5 & 94.8 \\
Argentina & 7.398 & 8.8 & 80.8 \\
Perú & 5.770 & 6.9 & 71.7 \\
México & 4.601 & 5.5 & 61.3 \\
Venezuela & 2.374 & 2.8 & 68.7 \\
Uruguay & 1.507 & 1.8 & 87.7
\end{tabular}

9 La explicación de la predominancia femenina en determinadas nacionalidades (República Dominicana, Nicaragua, Ecuador, México) necesitaría un estudio en profundidad sobre los factores diferenciales de las migraciones internacionales por sexo, aunque debe tenerse en cuenta que, dado el pequeño número de efectivos relevados, las diferencias entre varones y mujeres pueden no ser significativas. 
LINA BASSARSKY

CUADRO 2 (continuación)

\begin{tabular}{lrrr} 
Cuba & 1.482 & 1.8 & 71.7 \\
Guatemala & 1.178 & 1.4 & 95.4 \\
Ecuador & 1.157 & 1.4 & 58.9 \\
Bolivia & 939 & 1.1 & 76.8 \\
Salvador (El) & 729 & 0.9 & 70.7 \\
Paraguay & 551 & 0.7 & 83.1 \\
Nicaragua & 357 & 0.4 & 55.9 \\
Honduras & 352 & 0.4 & 71.7 \\
Dominicana (Rep.) & 331 & 0.4 & 53.2 \\
Costa Rica & 307 & 0.4 & 81.7 \\
Panamá & 261 & 0.3 & 72.8 \\
\hline América Latina & $\mathbf{8 3 . 9 8 7}$ & $\mathbf{1 0 0 . 0}$ & $\mathbf{7 6 . 8}$
\end{tabular}

Fuente: INSEE: 2002 (RP 1999, explotación principal, cuadro CD-N2)

GRÁFICO 2

ESTRUCTURA DE LA POBLACIÓN INMIGRANTE DE AMÉRICA LATINA Y EL CARIBE. FRANCIA METROPOLITANA, 1999

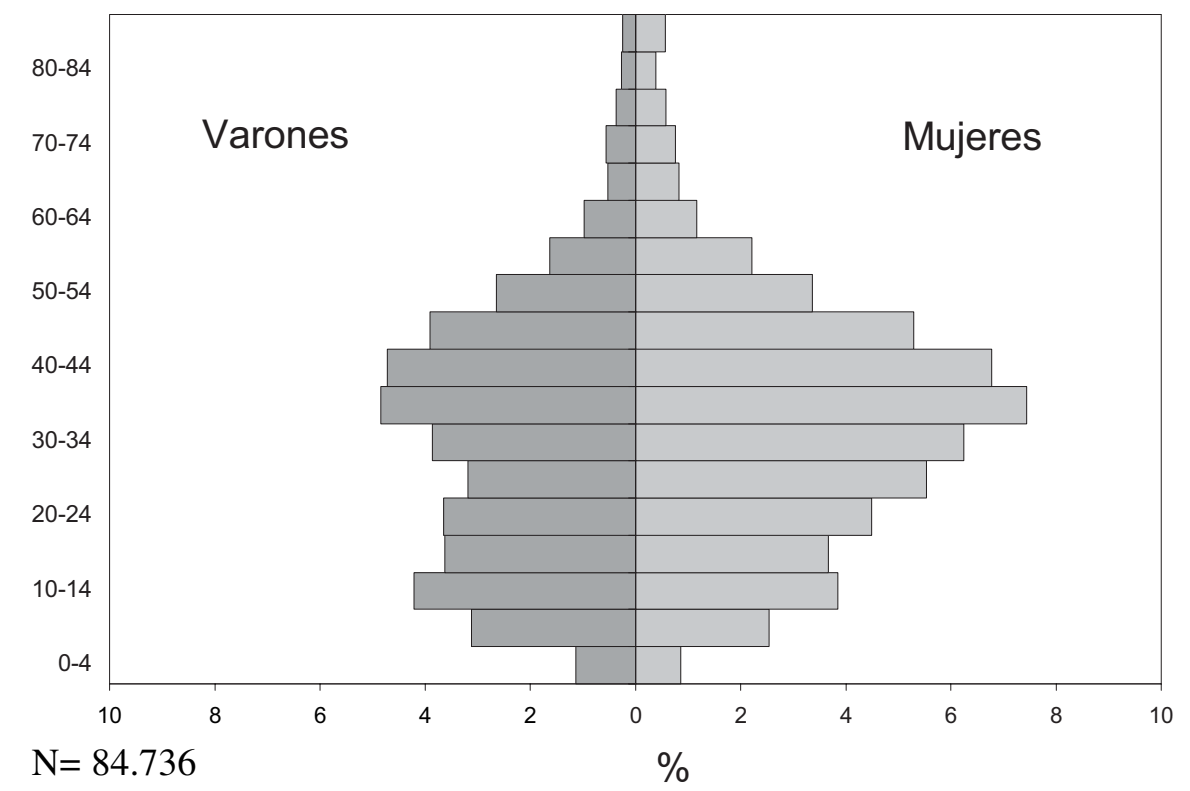

Fuente: INSEE: 2002 (RP 1999, explotación complementaria, cuadros CD-P2B). 


\section{Mecanismos migratorios de América Latina hacia Francia y redes sociales}

Un conjunto de trabajos han estudiado, desde diferentes perspectivas, los cuatro flujos migratorios que hemos seleccionado. Nuestra mirada comparativa nos permite rastrear en ellos la idea de base que hemos retenido para la observación de redes sociales, la de estructuras de relaciones sociales duraderas. A partir de esta idea general, intentaremos describir sus características y funciones, retomando la distinción realizada por D. Gurak y F. Caces ${ }^{10}$ de tres tipos principales de funciones cumplidas por las redes migratorias: la adaptación, la selección y la canalización.

La función de adaptación incluye el acomodamiento a corto plazo a las condiciones temporarias de llegada frecuentemente difíciles, tanto como la integración a largo plazo en las instituciones principales de la sociedad de destino. La selección se refiere a los procesos de determinación de qué individuos serán los que migran. La canalización hace hincapié en los mecanismos de transmisión de recursos, especialmente de información. Este último enfoque puede ser emparentado a las teorías difusionistas de las redes sociales.

\section{Las migraciones de exilio: redes de información y solidaridad}

Con el golpe de estado de 1964 en Brasil se abre en América Latina un período de dictaduras militares que se prolonga a lo largo de la década de los setenta, seguido por un no menos penoso período de violencia política durante los ochenta, especialmente en Centroamérica. Dichos contextos de terror han impuesto el exilio como estrategia de supervivencia y de búsqueda de bienestar a un importante número de latinoamericanos. Los principales países receptores durante esa etapa fueron España, Alemania, Francia, Suecia, Italia, Holanda, Gran Bretaña e Israel, además de algunos países de la región, como Venezuela y México. El continente europeo ha

10 Gurak, Douglas, y Caces, Fe: "Redes migratorias y la formación de sistemas de migración" en Malgesini, G. (comp.): Cruzando fronteras. Migraciones en el sistema mundial, Ed. Fundación Hogar del Empleado / Icaria Ed., Barcelona, 1998. Su versión original puede encontrarse en: Gurak, Douglas, y Caces, Fe: "Migration networks and shaping of migration systems", en Kritz, Mary; Lim, Lean, y Zlotnik, Hania (eds.): International migration systems: a global approach, Clarendton Press, Oxford,1992, págs. 150-176. 
significado con frecuencia el destino final de una circulación migratoria forzada, como la de numerosos paraguayos, chilenos y uruguayos que, habiendo partido a Argentina o México, han debido volver a emigrar a causa del deterioro político institucional en esos países. ${ }^{11}$

Por aquella época Europa imponía fuertes medidas restrictivas a la inmigración de trabajo, como consecuencia de la crisis económica desatada en 1973. El "cierre de fronteras" marcó el fin de una política explícita de inmigración de trabajo, llevada a cabo en la década anterior, durante el período de reconstrucción económica de la segunda posguerra.

El estado francés, que otorgaba el estatus de refugiado, acogió a un número importante de latinoamericanos, entre ellos originarios de Chile y Argentina, a pesar de las medidas fuertemente restrictivas de control migratorio que el estado francés había implementado a partir de 1974.

Redes de diversa índole parecen haber actuado en distintos "momentos" de la experiencia de exilio. En el momento inicial, las redes de información se movilizaron para ofrecer posibles lugares de asilo (función de selectividad y canalización), dando lugar a la circularidad migratoria hacia el interior y exterior de la región latinoamericana. En un segundo momento, las redes institucionales de partidos políticos, organizaciones civiles, sindicatos, instituciones religiosas y círculos de intelectuales cumplieron un rol fundamental para la acogida y la integración social y laboral de los exilados (función de adaptación a corto y largo plazo). En un crítico tercer momento, las redes sociales actuaron posibilitando el retorno y la reinserción en el país de origen (adaptación que incorpora los lazos con la sociedad de origen). Finalmente, y menos frecuente, se ponen de manifiesto los contactos reactivados para posibilitar la partida de los descendientes hacia las sociedades que habían anteriormente acogido a sus padres (selectividad y canalización).

En la literatura sobre las experiencias de migraciones políticas, muy frecuentemente aparece la expresión de "redes de solidaridad" para referirse al dispositivo institucional, tanto de acogida, de apoyo a la inserción social de los inmigrados, como de denuncia de las violaciones de derechos humanos o de militancia política. Dicha solidaridad — con sus múltiples y complejas manifestaciones- puede ser vista, entonces, como el principio organizador de dichas redes.

11 Pellegrino, Adela: "Migration from Latin America to Europe: Trends and policy challenges", IOM Migration Research Series, n. ${ }^{\circ}$ 16, mayo, International Organization for Migration, 2004. 
El carácter de las mismas parece ser de fuerte formalización, es decir, de acción coordinada entre partidos políticos, organizaciones civiles y otras instituciones de la sociedad. También suele resaltarse los dos niveles de la acción solidaria: el institucional y el de las redes de relaciones interpersonales, cada una con dinámicas propias; ambas no exentas de contradicciones y conflictos.

La segunda mitad de la década de 1970 estaba impregnada por un clima de época en el que predominaban sensibilidades humanitarias y de defensa de los derechos humanos.

Desde la teoría del capital social (ver recuadro 1), podría quizás también aludirse al concepto de solidaridad confinada,${ }^{12}$ haciendo referencia a un tipo de fuente de recursos (en este caso provenientes de las organizaciones e individuos que conformaban tales "redes de solidaridad") motivada por un sentido altruista. Dicha fuente de capital social da cuenta de la transferencia de información y recursos debido a un sentido de membresía o lealtad con determinado grupo social.

La importante movilización y acogida a los exilados chilenos a partir de 1973 desempeñó un rol importante como antecedente para las manifestaciones y mecanismos de solidaridad desplegados por la sociedad francesa, hacia los exilados y organizaciones argentinas que llegaban a partir de 1976-1978. ${ }^{13}$ En cuanto a este segundo movimiento de exilio, es posible distinguir dos niveles de acción, el institucional y el individual, cada uno con sus alcances y limitaciones.

En cuanto al primer nivel evocado, el institucional, el organismo oficial de acogida encargado entre otras tareas de otorgar el estatus de refugiado a los exilados, la OFPRA (l'Office de Protection des Réfugiés et Apatrides), actuó en coordinación con un conjunto de entidades privadas de diversa índole, como France, Terre d'Asile, entre otras. La acción soli-

12 Portes, Alejandro, y Sensenbrenner, Julia: "Embeddedness and Immigration: Notes on the Social Determinants of Economic Action", American Journal of Sociologie, n. ${ }^{\circ}$ 98, 1993, págs. 1320-1350.

13 Existiendo una amplia bibliografía sobre este tema, nos referimos aquí sólo a las siguientes obras. Sobre el exilio chileno: Gaillard, Anne Marie: Exils et retours. Itinéraires chiliens, L'Harmattan, Paris, 1997; para el caso argentino: Franco, Marina: Les émigrés politiques argentins en France (1973-1983). Certaines expériences et trajectores, tesis de doctorado bajo la dirección de Pilar González Bernaldo e Hilda Sábato, Université Paris 7 y Universidad de Buenos Aires, Buenos Aires, 2006. Consultamos además la obra de Sáenz Carrete, Erasmo: El exilio latinoamericano en Francia 1964-1979, Potrerillos Ediciones, Universidad Autónoma Metropolitana, México, 1995. 
daria era además desarrollada por otro conjunto de instituciones de carácter humanitario, vinculadas a la denuncia de violaciones de los derechos humanos, como Amnesty Internacional, pero también otras directamente ligadas al contexto latinoamericano, como la Association de Parents et Amis de Français Disparus en Argentine et Uruguay, entre otros. Se distinguen además las acciones de los órganos políticos, los llamados "comités de solidaridad", los propios partidos políticos de izquierda y las acciones de las organizaciones sindicales (especialmente la CGT y la CFDT ).

Dada la amplia gama de instituciones involucradas, sería apropiado hablar de diversas "redes" de acción, observando que la solidaridad pudo ser motor de acción en algunos casos, y encontrarse entre intereses más o menos marginales en otros. Como señala M. Franco, la solidaridad interorganizacional tuvo límites claros en el tiempo (con el mayor activismo entre 1978 y 1980) y también en su dinamismo. En efecto, la acción de tal complejo entramado de grupos argentinos y franceses conllevaba necesariamente conflictos internos e intereses encontrados que limitaron, condicionaron o más bien moldearon la "solidaridad" hacia los exilados.

Dichos límites observados a nivel institucional se encuentran ausentes en las manifestaciones de solidaridad interpersonal - aun entre personas que forman parte de las mismas redes institucionales-. Es decir, la dinámica interpersonal ha dado lugar a un funcionamiento distinto a la institucional, incluyendo relaciones de apoyo y cooperación tanto por parte de los franceses, como de inmigrantes argentinos ya instalados en Francia.

Respecto del complejo proceso de retorno al país de origen, el caso del exilio chileno nos sirve de ejemplo para analizar el rol de las redes que se activan para posibilitar el regreso. Aquí, la lógica de la red se sitúa más bien en el nivel de los lazos familiares, de amistad y también políticos que mantienen los exilados con sus países de procedencia. El retorno ha sido en muchos casos percibido como un derecho fundamental de la persona negado por la dictadura. En el caso de los chilenos en Francia, el movimiento "Pro-retorno" ha cristalizado las luchas contra el poder dictatorial en Chile. Esta dinámica forma parte de la concepción profundamente anclada en el pensamiento de que el retorno constituía un deber. Para afrontar el retorno, una infraestructura de movimientos asociativos y financiados por fondos extranjeros se instaló para ayudar a los "retornados" a reintegrarse en su país. 
REDES SOCIALES EN LAS MIGRACIONES DE AMÉRICA LATINA HACIA FRANCIA

\section{RECUADRO 1}

\section{RED Y CAPITAL SOCIAL}

Actualmente, uno de los planteamientos que integra con mayor fecundidad la noción de redes, las concibe como mecanismos de movilización de capital social. La clásica definición de P. Bourdieu de capital social constituye el primer análisis sistemático al que siguió un vasto desarrollo teórico, aplicaciones y vertientes no ajenas a las divergencias entre tradiciones disciplinarias dentro de las fragmentadas ciencias sociales. Recordemos que para P. Bourdieu, el capital social es "la suma de los recursos reales o potenciales ligados a la pertenencia de una red duradera de relaciones más o menos institucionalizadas de conocimiento y reconocimiento mutuo". ${ }^{14}$ Es, además, el canal a través del cual ciertas formas de capital se transmutan en otras (capital humano, financiero, cultural). En otros términos, el capital social es entendido como la capacidad de obtener recursos materiales e información (sobre búsqueda y acceso al empleo, vivienda, transporte, ayuda financiera, etc.) a través de la pertenencia a las redes interpersonales. No trataremos aquí sobre la vasta discusión acerca de los diferentes enfoques existentes de esta noción. Notemos solamente que la mayoría de proposiciones sostienen, para el caso de los inmigrantes, que el capital social reduce los costes ligados al desplazamiento, la instalación, la búsqueda de empleo, la inserción social en la sociedad de destino y la reproducción cotidiana de la familia en la sociedad de origen, etc.

Sin embargo, si el capital social es, como vemos, una capacidad que contribuye de manera positiva a las estrategias de vida, no son raras las referencias a los aspectos negativos o disfuncionales de la pertenencia a un determinado tipo de red. Si la red social del inmigrante se cierra en lo que puede ser visto como una "comunidad" inmigrante, cada forma de inclusión social y de pertenencia a tal red puede ser asimismo concebida como una forma de exclusión respecto a los espacios o personas que no pertenecen a la misma. Esto remite al complejo debate sobre los modelos de integración social de los inmigrantes, debate que ciertos autores ya empiezan a plantearse con respecto a los latinoamericanos en Francia.

14 Bourdieu, Pierre: "Le capital social. Notes provisoires", Actes de la recherche en sciences sociales, 1980, n. ${ }^{\circ}$ 31, enero, págs. 2-3. También en: Bourdieu, Pierre: "The forms of capital", en Richardson, J. (ed.): Handbook of Theory and Research for the Sociology of Education, Greenwood Press, New York, 1986, págs. 241-258. 


\section{La "fuga de cerebros": capital social especializado y redes institucionales}

Un segundo ejemplo, dado por la emigración de intelectuales, profesionales y técnicos altamente calificados, representa un tipo particular de mecanismo de selección a través de mercados laborales especializados. El mismo difiere del clásico esquema de la integración laboral de los inmigrantes en mercados de trabajos secundarios (ver recuadro 2).

Las expresiones "migración calificada", "éxodo de competencias" o "fuga de cerebros" frecuentemente se refieren a fenómenos de carácter variado: la migración circular de empresarios internacionales, las redes entre investigadores y profesores de los países de inmigración y de emigración, incluso la movilidad de estudiantes. Al contrario de lo que sucede en otros tipos de movimientos migratorios, las redes a las que pertenecen los inmigrantes calificados parecen estar muy ligadas a programas políticos ad hoc. Por otro lado, a diferencia de las redes sociales que analizaremos en los siguientes dos apartados, una característica singular de este tipo de organizaciones es que en muchos casos son construidas explícitamente en tanto "redes", es decir, se autodesignan como tal y explicitan desde su origen el principio organizador que las sostienen.

La coordinación de un conjunto de investigadores que se disponen a trabajar en "red" está ligada al movimiento a la vez político, teórico y científico que propuso transformar el brain drain en brain gain, gozando de un eco significativo en América Latina.

Durante los años 1970 y 1980, el estudio de las migraciones calificadas desde los países en desarrollo hacia las sociedades desarrolladas había estado situado en el seno del debate sobre la dependencia de los países "periféricos" respecto de los países "centrales", en tanto que constituía uno de los factores de empobrecimiento y de pérdida definitiva de recursos humanos para las sociedades de origen. Las nociones de "fuga de cerebros" (brain drain) o de inversión de la transferencia de tecnología hacían referencia a este fenómeno. Hacia mediados de los noventa, desde organismos internacionales se propone un cambio en la teorización de este tipo de migración, proponiéndose nuevos conceptos, con el fin de explorar la existencia de "efectos positivos" en las sociedades que expulsaban sus "cerebros". El interés se centraba en explorar en qué medida la migración calificada podía transformarse en una fuente de desarrollo o en 
una ventaja potencial para los países de origen. En este sentido, sin subestimar del todo los aspectos negativos del brain drain, los conceptos de brain gain y de brain circulation intentaban describir los fenómenos que permitirían superar o compensar las "pérdidas" de recursos producidas por la emigración.

Para esto, una de las estrategias llevadas a cabo era la de transformar a los inmigrantes en nexos entre la redes locales y globales de desarrollo científico y tecnológico, es decir, en agentes individuales o colectivos de transferencia de conocimiento y tecnología. ${ }^{15}$

La "circulación de cerebros" corresponde a la noción de "circulación migratoria" aplicada al campo de la migración calificada. Se refiere al número creciente de inmigrantes calificados que retornan al país de origen después de una estancia en otro país. Este tipo de movimiento facilita la formación de redes de inmigrantes y no inmigrantes a través de la movilidad de recursos humanos, que en particular concierne el sector de la ciencia y la tecnología, ya sea en el sector público o privado. Las relaciones se establecen entre actores individuales o colectivos, locales e internacionales, de desarrollo científico, tecnológico y académico, constituyendo redes de transferencia de conocimientos, información y tecnología.

Podría pensarse en un cierto paralelismo entre este enfoque y lo que hoy se plantea en términos de "co-desarrollo". En efecto, si el brain gain concebía el aporte de parte de la población residente fuera de su país de origen al desarrollo científico y tecnológico del mismo, en la actualidad son las remesas (ingresos transferidos por los inmigrantes a sus familias destinados esencialmente al consumo) el aporte fundamental visto como recurso a "capturar" para ser reinvertido en el desarrollo del país de origen. Sin duda, estos planteamientos, que recuperan la importante dimensión de los lazos que mantienen los inmigrantes con sus sociedades de origen, no se encuentran ajenos a controversias y debates.

Otro tipo de funcionamiento reticular observado ha sido el intercambio de información, en particular a través de Internet, como parte de los procesos de "desterritorialización" de la migración (idea ligada a la de "comunidades transnacionales", objeto de un debate que no abordaremos en este artículo). Al respecto, debe recordarse que el tema de la inmovili-

15 Pellegrino, Adela: "Éxodo, movilidad y circulación: nuevas modalidades de la migración calificada", en Comisión Económica para América Latina y El Caribe (CEPAL): La migración internacional y el desarrollo en las Américas, Simposio sobre migración internacional en las Américas, San José de Costa Rica, septiembre de 2000, Serie seminarios y conferencias, n. ${ }^{\circ}$ 15, 2001. 
dad de las personas interconectadas desde diversos puntos del planeta se sitúa de forma creciente en los debates actuales sobre la migración internacional.

Algunos antecedentes de investigación hacen referencia a redes de inmigrantes latinoamericanos que se formaron a finales de los ochenta, algunas de carácter espontáneo y otras institucionales. En el plano de los individuos que las constituyen, cabe apuntar — retomando nuestros comentarios precedentes sobre la rigidez de las categorías migratoriasque en muchos casos el exilio y la "migración de personas altamente calificadas" fueron para América Latina fenómenos yuxtapuestos, estrategias individuales o colectivas para afrontar situaciones político-institucionales adversas.

Una de las iniciativas más citadas es la de la conformación de la red CALDAS, como ejemplo de brain gain, cuyo objetivo era el de "asociar los intelectuales colombianos expatriados entre ellos y con su país, para que puedan contribuir, desde el lugar donde se encuentran, al desarrollo científico y técnico, así como socio-económico y cultural de Colombia." ${ }^{16}$ Dicha red nació bajo la iniciativa del gobierno colombiano (a través del organismo Colciencias), recibiendo el apoyo de los servicios diplomáticos del país.

Tratándose de una red formalmente institucionalizada, la superposición de diversos factores demuestra cómo la red articula para su funcionamiento las macro estructuras y la acción individual. Por un lado, las políticas de internacionalización de la ciencia y la tecnología llevadas adelante por el gobierno colombiano; por otro lado, los esfuerzos de los grupos de investigadores de Colombia por entablar relaciones de trabajo con los investigadores en el extranjero; y finalmente, estos últimos, con voluntad e interés de trabajar por el país de origen desde el país de residencia.

En la dinámica de funcionamiento de esta red se desarrollan tres procesos: un proceso de reconocimiento y convergencia entre los diferentes actores; un proceso de organización e institucionalización de la red, y un proceso de diferenciación. La diferenciación interna opera tanto a nivel de las "subunidades" (los nodos), como a nivel de los individuos.

Respecto al primer nivel, puede afirmarse que ciertos nodos ejercían influencia sobre otros. Tal es el caso del nodo de París creado en 1991 a

16 Nos basamos en: Meyer, Jean-Baptiste, y Charum, Jorge: “'La fuite des cerveaux' est-elle épuisée?”, Cahiers des sciences humaines, 31: 4, 1995, págs. 1003-1017. 
partir del interés de realizar acciones para fomentar el respeto de los derechos humanos en Colombia. Dicho nodo se extendió a España y Bélgica, obteniendo rápido reconocimiento por las autoridades colombianas.

En cuanto a la diferenciación a nivel de los individuos, la constitución de esta red institucional de investigadores no fue contraria a su heterogeneidad interna. Ésta se expresó en una gran diversidad - a veces conflictiva- de rasgos culturales, lingüísticos, de experiencias de vida según los distintos países o ciudades, de campos de investigación, de pertenencias a tradiciones de cooperación internacional según los países o las universidades, de formación, e incluso de estatus social y económico y de intereses por parte de los diferentes actores.

En resumen, la red CALDAS puede verse como un organismo que ha permitido ejercer influencias, ${ }^{17}$ un espacio móvil en el que los diversos actores involucrados movilizan su capital social para llevar adelante tanto objetivos comunes, como proyectos individuales.

Desde el punto de vista del pensamiento migratorio, puede ser vista como un caso de selectividad migratoria organizada; una red por la que la información se canaliza a través de campos especializados de conocimiento; que a su vez sirve a la adaptación de los inmigrantes a las sociedades de destino, así como de vinculación para su retorno.

En cuanto a los resultados obtenidos por las redes de científicos e investigadores como la que acabamos de reseñar, resulta evidente que este tipo de iniciativa constituye solamente una medida complementaria, que no puede ocupar el lugar de las políticas nacionales de formación de recursos humanos para el desarrollo social y económico del país. ${ }^{18}$ No tenemos conocimiento de la evolución reciente de la Red CALDAS, si bien sabemos que la misma no se encuentra más activa. Recientemente el Ministerio de Relaciones Exteriores de Colombia ha propuesto una nueva iniciativa, la "Red de estudiantes y profesionales colombianos en el exterior", que parece delinearse más como una red virtual de intercambio de información y prestación de servicios que como un mecanismo de colaboración institucional para el desarrollo científico y tecnológico del país. pág. 11.

17 El comentario pertenece a: Meyer, Jean-Baptiste, y Charum, Jorge: "La fuite des...",

18 Esto había sido señalado por Pellegrino, Adela: Migrantes latinoamericanos: síntesis histórica y tendencias recientes, CEPAL y Universidad de la República de Uruguay, Montevideo, 2001. Puede nuevamente notarse el paralelismo que puede establecerse con respecto al discurso más difundido actualmente sobre el posible aporte de las remesas, fenómeno que sin embargo no debe perder de vista la falta de verdaderas políticas de desarrollo para los países empobrecidos. 


\section{RECUADRO 2.}

\section{RED Y SEGMENTACIÓN DEL MERCADO DE TRABAJO}

Una multiplicidad de teorías ha intentado dar cuenta de la demanda de mano de obra inmigrante dentro de las estructuras económicas segmentadas de los países desarrollados. La lógica general subyacente reside en la existencia de un tipo de demanda estructural de trabajadores a partir de la formación de un sector de la economía caracterizado por trabajos inestables, de baja remuneración y en sectores de la economía de trabajo intensivo, que al no ser valorizados por la población local, requiere la incorporación de inmigrantes (principio primordial de la "teoría del doble mercado de trabajo" elaborada por M. Piore en los años setenta). Esta lógica implicaría que la fuerza de trabajo inmigrante, inserta en este sector secundario, resulta complementaria y no competidora respeto a la fuerza de trabajo local.

Por otra parte, el estudio de la incorporación de personas de alto nivel de calificación — científicos, profesionales y técnicos - y de los llamados "talentos", apreciados en el mundo desarrollado, conduce a concebir diversos tipos de segmentación, no sólo "por abajo" sino por "por arriba" de la escala socioocupacional.

Otras teorías suponen la influencia de variables culturales propias del colectivo inmigrante sobre la segmentación laboral, formándose un "tercer sector", el del enclave étnico (A. Portes) o de nicho étnico (R. Waldinger). ${ }^{19}$ En ambos casos se trata de explicar los diferentes mecanismos a través de los cuales en determinado sector (o subsector) de actividad prevalece, en un momento determinado, cierto grupo étnico o nacional. Las razones y consecuencias de la conformación de tal "tercer sector" son complejas y divergentes según los diversos casos estudiados y según los niveles sobre los que se focalice el análisis: el de la estructura de oportunidades del mercado laboral general, el de la interacción entre empleadores y empleados que participan de tal sector, en fin, el de la posición de aquellas personas ajenas a tal red con base "étnica".

Desde los enfoques de redes personales, uno de los argumentos más ampliamente desarrollado es el propuesto por M. Granovetter (de manera no exclusiva al caso de migrantes) sobre la "fuerza de los lazos débiles". ${ }^{20}$ En tér-

19 Rea, Andrea, y Tripier, Maryse: Sociologie de l'immigration. Col. Repères, La découverte, Paris, 2003.

20 Granovetter, Mark: "The strength of weak ties", American Journal of Sociology, vol. 78, n. ${ }^{\circ}$ 6, 1973, págs. 1360-1380.Ver también: Granovetter, Mark: "The strength of weak ties. A network theory revisited”, Sociological Theory, vol 1, págs. 201-233. Una traducción en español apareció en: Requena Santos, Félix: Análisis de redes sociales... (ver nota 1). 
REDES SOCIALES EN LAS MIGRACIONES DE AMÉRICA LATINA HACIA FRANCIA

\section{RECUADRO 2 (continuación)}

\section{RED Y SEGMENTACIÓN DEL MERCADO DE TRABAJO}

minos simples, éste sostiene que los lazos fuertes que posee el ego (grupo de parientes, de amigos íntimos) suelen estar solapados entre sí, de manera que la estructura que se conforma es "densa", poco permeable a la introducción de información novedosa, útil, por ejemplo, para la búsqueda de oportunidades laborales, o, en otras palabras, donde la información es redundante. En cambio, los lazos débiles (los “conocidos" y otras relaciones no cercanas) pertenecen a otras redes densas, de manera que es más probable que algunos de ellos actúen como puentes hacia redes donde circula información valiosa para ego. En resumen, esta visión focalizada sobre el uso instrumental de los lazos señala que existe mayor probabilidad de que la inserción en redes sociales densas obstruya procesos de movilidad, particularmente respecto al mercado de trabajo.

Ahora bien, estos argumentos han planteado una serie de controversias respecto a la teoría según la cual las redes de migrantes (mayoritariamente densas en lazos fuertes) son un canal efectivo que favorece el acceso a la información, la inserción laboral, etc. En este sentido, se podría cuestionar la propia evaluación del significado de capital social, si se entiende como tal la obtención de recursos que nacen de la pertenencia a redes de relaciones duraderas (Ver recuadro 1). Sin embargo, más que refutar una u otra teoría, estas discusiones dan cuenta de la necesidad de base empírica. En particular, distintos estudios han mostrado que el rol de los lazos fuertes o débiles varía según características individuales como la clase social, el tipo de información que circula, el tipo relación establecida con los lazos débiles (de puentes o no), las variables contextuales que afectan las relaciones, la evolución de las redes en el tiempo, etc.

\section{Algunos rasgos de una migración laboral. Migración en cadena y economía "étnica"}

En términos de la movilidad poblacional, una cadena migratoria se refiere al mecanismo a través del cual determinados flujos se perpetúan, gracias a condiciones creadas a partir de un grupo de inmigrantes pioneros. Se trata de la observación de la parte del proceso migratorio que corresponde al mantenimiento de un flujo determinado, una vez que éste se inició, a pesar de que los factores que impulsaron los movimientos iniciales han per- 
dido su pertinencia. De este tipo de migración nos ilustran algunos estudios sobre la comunidad colombiana en Francia. ${ }^{21}$

Como consecuencia de la combinación de factores de crisis económicos y político-institucionales, la migración de un conjunto numeroso de pioneros trabajadores colombianos a partir de los años ochenta dio lugar a la conformación de una red migratoria de trabajo, entre estos inmigrantes y sus empleadores, antiguos inmigrantes portugueses y españoles insertos en el sector de la construcción, más específicamente en el de la pintura de edificios. Así, esta primera inserción laboral permitió el desarrollo de una migración familiar y de vecindad hacia Francia, que favoreció posteriormente su instalación definitiva, dando lugar a proyectos de movilidad social y favoreciendo una nueva dinámica de migración.

Esta migración se caracteriza principalmente por una procedencia común, dado que alrededor de un $70 \%$ de los individuos viene del pueblo de 5.000 habitantes de Santuario-Risaralda y de la ciudad de Cartago, de 100.000 habitantes. Ambas localidades se encuentran situadas en la zona cafetera, no ajenas a conflictos de violencia político institucional.

Durante los años noventa, un proceso de movilidad social ascendente favoreció el desarrollo de un pequeño empresariado de antiguos obreros del sector de la pintura de edificios, que a su vez reclutaba mano de obra colombiana. Este pequeño empresariado étnico posibilita la perpetuación del flujo migratorio, formándose así una segunda cadena migratoria, basada en lazos tejidos a partir de una la procedencia común.

La función principal de esta red sería, entonces, la de proporcionar un tipo específico de adaptación a la sociedad de destino, basada en una "economía étnica" o "inmigrante", en el marco del mercado laboral segmentado de la sociedad francesa.

Este ejemplo puede ser ilustrativo del fenómeno ampliamente evocado de clausura social, ${ }^{22}$ por la cual el reclutamiento por redes puede dar lugar a relaciones de dependencia e interdependencia no solo entre los propios inmigrantes que se agrupan entre sí, sino entre empleados y empleadores. En el caso que describimos aquí, una consecuencia negativa de este

21 Nos basamos en los trabajos de: Gincel, Anne: L'immigration des Colombiens en France, tesis de doctorado bajo la dirección de Étienne Le Roy, Université Panthéon-Sorbonne, Paris, 2005; Luna Porras, Álvaro: Les migrations colombiennes: travailleurs colombiens dans le bâtiment à Paris, memoria de DEA, Université Paris 3, IHEAL, Paris, 1998.

22 Waldinger, Roger: "Social capital or social closure?: Immigrant networks in the labor market”, Working Paper, The Lewis Center for Regional Policy Studies, n. ${ }^{\circ}$ 26, 1997. 
fenómeno de clausura ha sido el ejercicio de relaciones de explotación y abuso por parte de los empleadores hacia sus empleados compatriotas, especialmente en lo relativo a la irregularidad o a la falta de pagos (lo que sin duda no debe interpretarse como un fenómeno exclusivo o causado por este tipo de organización del trabajo).

La teoría sobre el capital social nos indica que los procesos de clausura social que emanan de las redes migratorias implican relaciones de poder, porque justamente se ponen en juego diversos recursos (capital social) que nacen de dichas redes. Sin embargo, las relaciones de poder no siempre son unidireccionales ni reproducen de manera rígida las jerarquías presentes en la estructura social. Por el contrario, dichas relaciones pueden ser complejas, existiendo entre los miembros de determinada red social ciertos sobrentendidos, normas informales o contratos implícitos, desconocidos por aquellos que no pertenecen a tal red, que son difíciles de romper.

Tales procesos de clausura social se encuentran presentes no sólo en los mecanismos de reclutamiento laboral étnico, sino también en otros ejemplos de relaciones sociales inmersas en redes migratorias.

\section{La "diáspora" haitiana: lazos "fuertes" y circulación de información}

El uso del concepto de diáspora se encuentra ligado a la idea de un desastre fundacional (guerra, persecución, masacre, etc.) que ocasiona la dispersión masiva de un pueblo. Más recientemente, el sentido de la palabra se ha visto ampliado para resaltar los lazos que ligan a grupos de inmigrantes con sus sociedades de origen, comprendiendo las prácticas culturales transnacionales a través de redes familiares, lazos asociativos, comerciales, políticos. Otras dos ideas caracterizarían la diáspora: por un lado, la percepción de sí en el espacio sería una percepción de extraterritorialidad, propia de la situación de dispersión geográfica; ${ }^{23}$ por otro lado, la voluntad de un proyecto identitario común. Dichas relaciones al espacio y a la identidad de grupo distinguirían la dinámica de diáspora de otras lógicas de redes transnacionales.

23 Dorai, Kamel; Hily, Marie-Antoniette, y Ma, Mung, Emmanuel: "La circulatin migratoire. Bilan des Travaux", Migration Études, Synthèse de travaux sur l'imigration et la présence étrangère en France, n. ${ }^{\circ} 84,1998$. 
Ahora bien, si la migración haitiana es frecuentemente descrita como una diáspora, esto se debe a su relativa importancia numérica,${ }^{24}$ surgida de una economía nacional de extrema pobreza y dependencia, y dispersa en el espacio (es decir, en diversos destinos y geográficamente distantes unos de otros). En efecto, la historia social y política del país ha dado lugar a una emigración producto de la exclusión y de la miseria, que siguió a otra compuesta por las elites intelectuales, en oposición a la migración de otras islas hacia las antiguas metrópolis (ver recuadro 3). Estas características explican, en parte, por qué la referencia a la emergencia de una diáspora se aplicó rápidamente, mientras que ésta no se observa en las otras comunidades caribeñas emigradas en el mundo.

El trabajo de C. Délanchet Guillon ${ }^{25}$ proporciona un ejemplo del funcionamiento de diversas redes sociales cerradas en el interior de un grupo de inmigrantes, donde la información resulta un elemento central de las relaciones reticulares entre individuos. Refiriéndose a datos obtenidos a partir de entrevistas realizadas a haitianos en la región parisina, el autor observa los rasgos de una red por la cual circula información sobre las oportunidades y las condiciones de vida entre los inmigrantes más recientes, originarios de zonas rurales y urbanas. ¿Cuáles son los canales de circulación de la información? Pueden distinguirse básicamente tres, según su grado de institucionalización:

En primer lugar, las dos confesiones que estructuran en mayor medida la comunidad — católica y protestante—, así como las demás confesiones minoritarias, parecen representar las vías de comunicación e interacción principales. En segundo lugar, las múltiples ocasiones informales, sociales y culturales que promueven el encuentro de un número importante de personas constituyen, según el autor del estudio, el sistema de comunicación más eficaz. Dichos encuentros son organizados por asociaciones de carácter político o cultural, pero son poco representativos del conjunto de inmigrantes y su existencia es frecuentemente efímera. Entre estas instituciones existen aquellas que son más permeables a la sociedad francesa, cuyos integrantes son tanto de nacionalidad francesa (en algunos casos ori-

24 Aunque relativamente moderada respecto a las tasas de emigración de las otras islas caribeñas. Ver al respecto: Domenach, Hervé: "L'évolution au XXe siècle du système démographique et migratoire caribéen" en Dewitte, Philippe, y Cohen, James (coord.): “ Diasporas caribéennes”, Hommes et Migrations, n. ${ }^{\circ}$ 1237, Paris, 2002.

25 Délachet Guillon, Claude: La communauté haïtienne en Ile-de-France, L'Harmattan, Paris, 1996. Se trata de un estudio llevado a cabo en 1994, que consiste principalmente en entrevistas con 50 informantes clave. Contiene tamién una pequeña encuesta cuantitativa por cuestionario estructurado. 
ginarios de las Antillas) como haitiana, y aquellas caracterizadas por estar organizadas alrededor de encuentros culturales o sociales entre compatriotas. Finalmente, hay que aludir a las redes no formales que se tejen a partir de relaciones familiares y de amistad más cercanas.

A pesar de la existencia de estos canales que podríamos calificar de reticulares, la comunidad haitiana en Francia se distingue por su fragmentación. La división social y la desconfianza hacia los otros -inclusive en el interior de la propia red- producen un efecto de deformación o parcialización de la información. Al respecto, cabe destacar una consecuencia paradójica: la información se propaga permitiendo resolver problemas de orden práctico; esto hace que cada cual logre desenvolverse de manera individual, sin deber apelar a solidaridades colectivas, de las cuales en muchos casos se desconfía, quizá debido a la experiencia de un pasado particularmente adverso en Haití.

De este modo, la comunidad instalada en Francia parece reproducir las divisiones sociales existentes en Haití. Y esto se observa en Francia "quizás aún con mayor vigor y crispación, dado que el modo de vida en la región parisina vuelve más compartimentados los diferentes grupos sociales que en Haití, donde en una región dada, todo el mundo conoce a todo el mundo. Los estudiantes que se encuentran actualmente en la metrópolis no mantienen contactos con la masa de nuevos emigrantes de origen popular rural o urbano. En cuanto a la pequeña minoría perteneciente a la burguesía rica, la misma vive en un mundo aparte del de las familias populares haitianas." ${ }^{\prime 26}$ Aquí, la lógica de red basada en una pertenencia nacional o comunitaria parece no poseer un peso real.

Sin embargo, el libro del periodista haitiano F. Wiener Kerns ${ }^{27}$ se sitúa en una perspectiva notablemente diferente de la anterior, intentando mostrar otra realidad ("nadie puede ya más poner en duda la existencia de una verdadera comunidad haitiana en Francia"). Según este autor, la comunidad haitiana en Francia, aunque mucho más pequeña que la que reside en Estados Unidos, en República Dominicana o en Canadá, se distingue por la amplitud de su vida comunitaria. El testimonio de múltiples actividades asociativas, culturales, políticas de los haitianos que tuvieron lugar durante la década de 1990 implica una voluntad (inclusive política) de reactivar el discurso sobre un pueblo permanentemente en lucha.

26 Traducción propia de: Délachet Guillon, Claude: La communauté haïtienne... pág. 91.

27 Wiener Kerns, Fleurimond: La communauté haïtienne de France. Dix ans d'histoire 19912001, L'Harmattan, Paris, 2003. 


\section{RECUADRO 3}

\section{HAITÍ, UN CASO PARTICULAR DE EMIGRACIÓN LATINOAMERICANA}

Tempranamente independiente (1804) e intervenida tras la Segunda Guerra Mundial, Haití no conoció el proceso de descolonización de las otras islas caribeñas, lo que había engendrado un sistema migratorio propio de la región. Debe recordarse que éste es el país más pobre de América Latina. Con una población total de alrededor de 8.400 .000 personas, la esperanza de vida era de solamente 59,2 años en 2000, respecto a una esperanza promedio de 71,2 años en América Latina. La mitad de su población de 15 años y en adelante es analfabeta. La atención primaria a la salud está reservada a una minoría, y menos de la mitad de la población tiene acceso a agua potable. ${ }^{28}$

La historia particular de este país ha dado lugar a diversas interpretaciones, a veces discordantes, que resaltan la complejidad en la relación entre Estado y Nación. Según el periodista A. Linard (Le Monde diplomatique, febrero 2004), en el momento de su independencia, el país estaba constituido por comunidades de diversos orígenes sin contar con ningún modelo de organización política. Así, el país se transformó en un Estado sin que existiera aún como nación. Después de dos siglos de historia, en la actualidad, el estadonación de Haití se encuentra aún en construcción.

El comienzo de los movimientos de emigración de la población haitiana puede situarse alrededor de los años cincuenta. La proximidad geográfica es un factor importante para determinar los destinos principales de estos movimientos, como sucede en todos los casos de migraciones asociadas a situaciones de crisis. Mientras que New York ha representado durante largo tiempo el destino privilegiado de los inmigrantes haitianos, existen asimismo otros lugares de llegada: Québec y los territorios franceses del Caribe (particularmente Guyana y Saint-Martin) por motivos de relativa facilidad lingüística, las Bahamas, las Islas Vírgenes y la Florida. ${ }^{29}$ La larga crisis política e institucional que ha suscitado una profunda crisis social no hace más que reforzar (o reactualizar) los factores de emigración.

En Francia, una primera inmigración haitiana data de los años setenta. Cuantitativamente débil y constituida mayormente por intelectuales, fue seguida desde 1980 hasta mediados de los noventa por una corriente compuesta por inmigrantes de origen popular. Como muestra el gráfico 3, según el censo de 1999, la población inmigrante en Francia proviene mayoritaria-

28 Centro Económico para América Latina y El Caribe (CEPAL): Anuario estadístico de América Latina, CEPAL, 2002.

29 Domenach, Hervé: L'evolution au XXe siècle... 
REDES SOCIALES EN LAS MIGRACIONES DE AMÉRICA LATINA HACIA FRANCIA

\section{RECUADRO 3 (continuación)}

\section{HAITÍ, UN CASO PARTICULAR DE EMIGRACIÓN LATINOAMERICANA}

mente de dichos años, lo que da como resultado una estructura de edades abultada en las edades activas tardías, alimentada además por generaciones más jóvenes (gráfico 4).

Debe recordarse, sin embargo, que, en términos generales, no son nunca las capas más pobres las que logran concretar un proyecto migratorio — más aún tratándose, como es este caso, de migraciones de largas distancias-, teniéndose en cuenta los costes (variables según el tipo de migración pero siempre significativos) del desplazamiento y la instalación. Actualmente, muchas familias de emigrantes en Francia se encuentran esparcidas entre este país, Canadá y los Estados Unidos. En algunos de estos casos, la circulación migratoria entre distintos países (lo que evidentemente requiere un capital financiero considerable) favorece el desarrollo de una especie de "cultura de la migración".

\section{GRÁFICO 3}

INMIGRANTES HAITIANOS SEGÚN EL AÑO DE LLEGADA A FRANCIA. FRANCIA METROPOLITANA, 1999

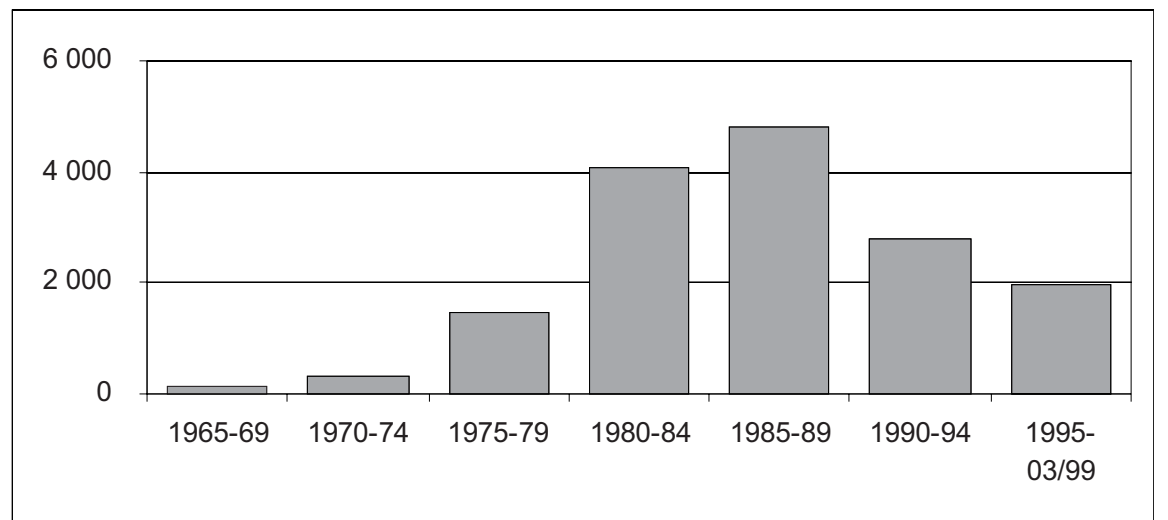

Nota: Debido a la fecha del censo, el último período no es un quinquenio. Fuente: Elaboración propia en base a INSEE: 2002 (RP 1999, cuadro AR1). 


\section{GRÁFICO 4}

ESTRUCTURA DE LA POBLACIÓN DE INMIGRANTES HAITIANOS. FRANCIA METROPOLITANA, 1999

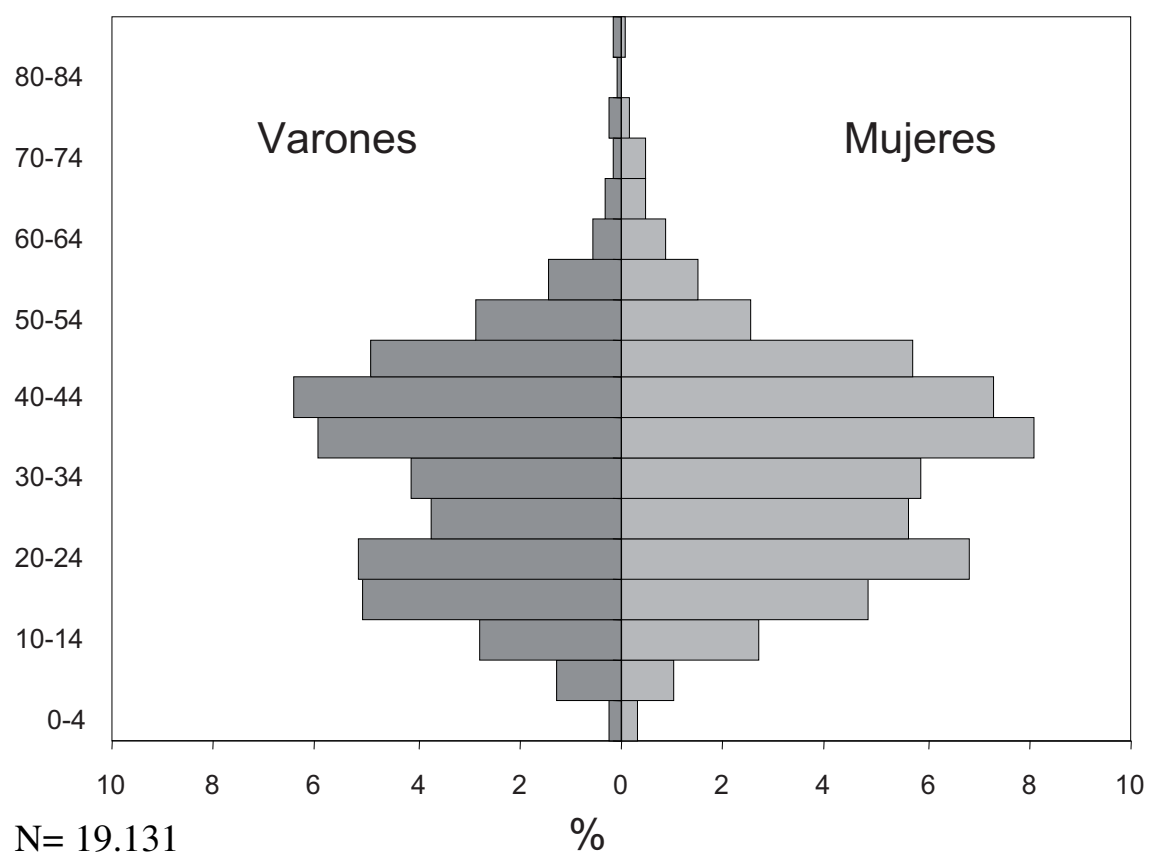

Fuente: Elaboración propia en base a: INSEE: 2002 (RP 1999, explotación complementaria, cuadro CD-P2B).

La comparación de los dos textos mencionados, el de C. Délanchet Guillon y el de F. Wiener Kerns, muestra dos puntos de vista alejados sobre las condiciones y experiencias de la vida de los haitianos en Francia. En última instancia, sin embargo, ambos ponen de relieve la formación de redes institucionales y personales (desde las redes familiares hasta las asociaciones políticas estructuradas) relativamente densas. Dichas redes estarían conformadas principalmente por "lazos fuertes" (relaciones estrechas de amistad o parentesco), serían socialmente homogéneas (de estudiantes, nuevos inmigrantes trabajadores, elites burguesas), con una débil presencia de "puentes", y donde la información circula de manera fragmentada. 


\section{Otras apliaciones posibles del concepto de red para el estudio de las migraciones latinoamericanas}

Una de las vías (aunque no la única posible) de sistematización del enfoque de redes sociales es la que emparenta las redes con mecanismos de movilización de capital social. Hemos hecho referencia en los apartados anteriores a dicha noción. El enfoque del capital social permite en teoría establecer relaciones con los demás tipos de capital -financiero, humano y cultural-, los tres con interesantes aplicaciones en el campo de las migraciones internacionales. Haremos referencia a algunas de las aplicaciones posibles en el caso de las migraciones latinoamericanas hacia Europa, que no fueron abordadas por los ejemplos seleccionados en los apartados anteriores.

En referencia al capital financiero, al tratarse de una migración de largas distancias que implica altos costes de desplazamiento, puede ser interesante analizar los mecanismos mediante los cuales los inmigrantes disponen de los recursos necesarios para cubrir dichos costes. Por otro lado, el tema de las remesas suscita gran interés en los estudios migratorios actuales. Existe ya un cúmulo significativo de estudios sobre las remesas que los inmigrantes latinoamericanos residentes en Estados Unidos transfieren a sus países de origen, de gran volumen e impacto relativo importante. En este sentido, la diversidad de perfiles migratorios de latinoamericanos actualmente presentes en el continente europeo permitiría realizar comparaciones novedosas sobre la existencia y el tipo diferencial de remesas transferidas por cada grupo.

En lo que respecta al capital humano, la importancia de la migración estudiantil de latinoamericanos hacia Europa ha comenzado a llamar la atención de investigadores y planificadores, porque se la considera una población muy móvil, cuyas estrategias y proyectos de retorno, circulación e instalación definitiva se redefinen a lo largo del tiempo. Además, esta migración renueva la preocupación por la problemática de la "fuga de cerebros", que había quedado algo relegada a partir de los años noventa.

En cuanto al capital cultural, asistimos actualmente a un intento de "etnisación" de los estudios migratorios en el contexto europeo, cuyos frutos en términos de producción de conocimientos científicos son objeto de pleno debate. Uno de los ejemplos al respecto lo constituye el de la inclusión de categorías "étnicas" en el censo de población francés, debate que, por otro lado, no es nuevo, pero se reactualiza a la luz de nuevas interrogaciones y nuevos fenómenos sociales. Otro de los campos de estudios ya 
abordados por los investigadores sociales se relaciona con la discriminación en el mercado de trabajo. En el caso del mercado de trabajo español se comienza a hablar de la "preferencia latinoamericana", observada en ciertos sectores de actividad, respecto del reclutamiento de inmigrantes provenientes de otras regiones, en particular de África del Norte.

En efecto, todos estos temas son objeto de estudio asociados al enfoque de redes sociales. Como última observación, valga señalar dos aspectos que, a nuestro entender, pueden resultar particularmente útiles en la profundización del uso de la noción de redes en el campo de las migraciones. Por un lado, la incorporación de la dimensión temporal que tenga en cuenta los cambios en su conformación y funcionamiento. Por otro, la preservación de su calidad de estructura de intermediación, es decir, que el énfasis puesto en los fenómenos "meso" no oscurezca - paradójicamente- la visión de los otros dos niveles de lo social, los fenómenos micro y las macro-estructuras.

\section{Conclusiones}

Nos hemos propuesto abordar desde una perspectiva comparativa el tema de las migraciones latinoamericanas hacia Francia, heterogéneas en cuanto a perfiles y orígenes migratorios. Para esto hemos retomado ejemplos de diferentes tipos de migraciones: el exilio, la "fuga de cerebros", la migración de trabajo y la diáspora. Nuestro objetivo ha sido el de desplazar el foco de atención desde las categorías macrosociales de clasificación de las migraciones hacia el nivel meso o de intermediación entre los comportamientos microsociales y los factores macrosociales. Los fenómenos observados en este nivel mostraron mecanismos de redes sociales que colaboraron en llevar a cabo los desplazamientos, acceder a fuentes de información de utilidad, e incorporarse social y laboralmente a la sociedad francesa.

Como conclusión de nuestro trabajo podemos señalar que los cuatro tipos de redes de latinoamericanos descritos ilustran cuatro usos considerablemente distintos del concepto de red y que todos ellos permiten poner en relación fenómenos de naturaleza macro y microsocial, en concordancia con su carácter de estructura de intermediación. Los usos del concepto de red a los que nos referimos son los siguientes:

-Los contextos sociopolíticos e institucionales de los países involucrados, en relación con las acciones individuales de ayuda mutua, frecuen- 
temente más efectivas que las institucionales, en el caso del complejo tejido de redes que fomentaron la acción solidaria hacia los exilados de Argentina y Chile durante las dictaduras militares de los años setenta.

- Las decisiones (y programas) tomadas por un gobierno en un momento sociopolítico particular, teniendo en cuenta sus recursos humanos altamente calificados residentes en el exterior, en relación con la "movilización de influencias" para la persecución de intereses personales, en concreto en el caso de las redes creadas con el fin explícito de asociar instituciones y profesionales colombianos que residieron fuera y dentro del país durante la década de los ochenta y principios de noventa.

- Las condiciones del mercado laboral segmentado de la sociedad francesa en el que se desarrolló una pequeña "economía étnica", puestas en relación con las dinámicas familiares y de contactos personales que perpetuaron las migraciones pioneras, concretamente en el caso de las cadenas migratorias conformadas por trabajadores colombianos que se insertaron en el sector de la construcción.

- Los canales institucionales de circulación de información y sociabilidad, en tensión con los comportamientos más bien individualistas en el seno de redes sociales densas de inmigrantes haitianos.

Siguiendo esta vía de trabajo, se debería intentar una mayor sistematización de las formas de describir, relacionar y explicar los fenómenos pertenecientes a los tres niveles de observación, empresa que dista de revelarse sencilla.

Recordemos finalmente, que nuestro punto de partida fue el de resaltar la relativa dispersión teórica del enfoque de redes en ciencias sociales, en general, y en el campo de las migraciones internacionales, en particular. Podríamos pensar que aquellas metáforas iniciales que sirvieron de inspiración a los precursores que darían origen al análisis social de redes a principios del siglo XX - que hacían referencia a las ideas de "grupo", "interconexión", "vínculo", "circularidad", etc.— son las mismas que en muchos casos hoy en día se utilizan de forma indistinta, haciendo un uso más bien vago del concepto de red social. No obstante, como tratamos de explorar en este trabajo, en la actualidad se constata que el enfoque de redes puede aportar conocimientos nuevos e interesantes desde una perspectiva mesosocial, sobre una gran variedad de modalidades migratorias tanto del pasado como del presente.

Recibido el 20 diciembre de 2006 Aceptado el 25 de febrero de 2007 